\title{
The function of mucins in the COPD airway
}

\author{
Wenju Lu • Jinping Zheng
}

Published online: 8 May 2013

(C) Springer Science+Business Media New York 2013

\begin{abstract}
Mucus clearance is the first defense of a normal airway against airborne pathogens and pollutants. However, mucus hypersecretion - an important feature of chronic obstructive pulmonary disease (COPD), especially the chronic bronchitis phenotype - contributes to disease pathology and mortality. Prescriptions of some mucoactive medications, e.g. $\mathrm{N}$-acetylcysteine and carbocysteine, have proved beneficial for COPD management. Mucins are large-molecular-weight glycoproteins which constitute the major solid components of mucus, giving mucus its viscous and elastic properties and enabling its defensive function. Most-expressed in the airway are three membrane-tethered mucins (MUC1, MUC4, and MUC16) and three gel-forming secreted mucins (MUC2, MUC5AC, and MUC5B). Although over-expression of all these mucins has been observed or postulated in COPD lungs, none has been specifically evaluated as affecting COPD. Evidence regarding immunosuppressive, bacterial-adhesive, anti-inflammatory, and tumorigenic effects of MUC1 in other disease conditions suggests MUC1 may contribute to immune suppression, airway remodeling, mucus obstruction, bacterial colonization, and disruption of epithelium integrity in COPD. Regulation of mucin synthesis and secretion is increasingly well understood. Mucin over-expression in COPD is probably caused by a combination of microbial products, airborne pollutants, and mediators of inflammation. Further studies are needed to determine the individual function and regulatory signaling of each mucin in COPD airways, with the objectives of better understanding the disease mechanism and of developing novel therapeutics for COPD treatment.
\end{abstract}

W. Lu $(\bowtie) \cdot$ J. Zheng $(\bowtie)$

State Key Laboratory of Respiratory Disease, Guangzhou Institute of Respiratory Disease, The First Affiliated Hospital of Guangzhou Medical University, 151 Yanjiang Road,

Guangzhou, Guangdong 510120, People's Republic of China

e-mail: wlu92@yahoo.com

e-mail: jpzhenggy@163.com
Keywords COPD $\cdot$ Mucus $\cdot$ Mucins $\cdot$ MUC1 . MUC5AC $\cdot$ MUC5B

\section{Introduction}

The global initiative for chronic obstructive lung disease (GOLD, 2011) defines COPD as a complex of diseases characterized by persistent airflow limitation, which is usually progressive and associated with an enhanced chronic inflammatory response of the airways and lungs to noxious particles or gases. COPD is a leading cause of morbidity and mortality worldwide, causing a substantial and increasing economic and social burden. The COPD diagnostic criteria are progressive dyspnea, chronic cough, chronic sputum production, history of exposure to risk factors (including tobacco smoke, smoke from home cooking and heating fuels, occupational dusts and chemicals), and a post-bronchodilator FEV1/FVC $<0.70$. Exacerbations of COPD airway disease may be caused by viral or bacterial infections, or by exposure to air pollutants. Bronchoalveolar lavage fluid (BALF) and induced sputum have increased neutrophil and macrophage levels. The submucosa of patients' small airways are chronically inflamed, with increased macrophages and T lymphocytes [1]. Depending on the cellular inflammatory profile, there are increased levels of IL-1 $\beta$, IL-6, IL- 8 , tumor necrosis factor- $\alpha$ (TNF- $\alpha$ ), and monocyte chemotactic protein-1 in induced sputum or BALF of patients with stable COPD [2]. Neutrophils and macrophages release proteases that contribute to inflammation and overwhelm anti-protease defenses. Reactive oxygen species (ROS) generated by cigarette smoke or by inflammatory cells may cause airway and parenchymal injury. Together, these inflammation mediators and products injure the airway, activating programs for structural changes to the airway wall (so-called airway remodeling) leading to airway narrowness and mucus obstruction. Structural changes to COPD airways include: 
mucus metaplasia, bronchiolar smooth-muscle hypertrophy, mural edema, peribronchiolar fibrosis, and excess mucus production in airways less than $400 \mu \mathrm{m}$ in diameter.

Of all pathological changes associated with COPD airway disease, mucus obstruction is the most prominent cause of airflow limitation and disease mortality, particularly for elderly patients and those prone to chest infections [3, 4]. Some mucoactive medications have been proved beneficial for COPD management $[5,6 \bullet \bullet]$. In this paper we review progress in understanding airway mucus and mucin biology, with emphasis on the less well-understood function of mucins in COPD airway disease.

\section{Mucus and mucin biology in the airway}

The airway epithelium is normally coated with a thin layer of airway surface liquid (ASL) and of gel-like mucus, which lies on top of the ASL. In large airways ( $>2 \mathrm{~mm}$ in luminal diameter) mucus is produced by goblet cells and by submucosal glands, whereas in small airways the only source of mucus is the goblet cell [7]. The general functions of mucus are protection, lubrication, and transport. Under healthy conditions, mucus maintains hydration in the airways and protects against inhaled pathogens, toxic gases, and other airborne pollutants via mucociliary clearance. Mucus also contributes to innate immune response in the lungs by transporting a variety of antioxidants, antiproteases, antimicrobial substances (e.g. defensins, lysozyme, and Ig A), immunmodulatory molecules (e.g. secretoglobins and cytokines), and protective molecules (e.g. trefoil proteins and heregulin) [8-10]. However, abnormal mucus production and clearance can cause airway obstruction and contribute to respiratory disease pathology $[11,12]$.

Mucus is approximately $97 \%$ water and $3 \%$ solids. Besides salts, lipids, polypeptides, cells, and cell debris, mucins are the chief constituents of the solid part of mucus [13]. Mucins are defined by their serine and/or threonine and/or proline-rich tandem repeat (TR) domains. They are very highmolecular-weight glycoproteins ( $\sim 3 \mathrm{MDa})$ [12], 50-90\% carbohydrate by mass and with dozens to several hundreds of O-glycosylation sites per molecule, the result of the large number of TRs in the protein backbone. On the basis of their cellular location, mucins are classified into two groups: membrane-tethered or secreted mucins. A subset of secreted mucins, the gel-forming mucins, have large, heavily $\mathrm{O}$ glycosylated apoprotein cores, and $\mathrm{N}$ and $\mathrm{C}$-terminal, cysteine-rich, von-Willebrand factor-like domains that participate in disulfide bond-mediated oligomerization. Once secreted, gel-forming mucins form very large ( 1 to $>10 \mathrm{MDa}$ ) viscoelastic macromolecular complexes, contributing to the elastic and viscous properties of mucus [14]. Membranetethered mucins may behave as receptors and participate in cell adhesion, glycocalyx generation, and airway defense; they may also be secreted into the mucus layer as the result of shedding or synthesis of splice variants lacking transmembrane domains $[15,16]$.

More than 22 mucin genes have been identified in the human and murine genome $[12,17]$. All but MUC2, MUC5AC, MUC5B, MUC6, MUC7, MUC8, MUC9, and MUC19 are membrane-tethered mucins [15, 16]. At least 14 mucin genes (MUC1, MUC2, MUC4, MUC5AC, MUC5B, MUC7, MUC8, MUC11, MUC13, MUC15, MUC16, MUC19, MUC20, and MUC21) are present at protein or mRNA levels in normal airways (Table 1) [12, 18-21]. MUC3 and MUC6 are expressed in well-differentiated NHBE cells cultured in vitro; their expression in normal bronchi is controversial [18, 21-23]. In normal sputum secreted mucins, mainly MUC5AC and MUC5B, comprise approximately $90 \%$ of mucin content, the remaining $10 \%$ mainly consisting of the three membrane-tethered mucins MUC1, MUC4, and MUC16 [24, 25].

In airway tissues from healthy individuals, mucins are produced by ciliated, basal, goblet, and submucosal-gland secretory cells in the upper and lower airway epithelia [12]. MUC1, MUC4, and MUC16 are the best-characterized of the membrane-associated mucins, and are mostly found at the apical surfaces of ciliated cells and Clara cells [21, 25]. MUC1 has also been detected in alveolar type-II epithelial cells $[26,27]$. MUC2 mRNA and protein are weakly expressed in the surface epithelium, in some goblet cells, within submucosal glands, in mucus cells, and in some serous cells; because of either its low expression or its insolubility, it is barely detectable in sputum $[14,21]$. MUC5AC is usually expressed by goblet cells, with some expression in the submucosal glands. The mucus cells of submucosal glands mainly produce MUC5B, with some expression of MUC8 and MUC19 [28, 29]. MUC6 is local to the bronchial and bronchiolar epithelium [23]; MUC7 is local to the serous cells of submucosal glands [30].
Table 1 Mucins expressed in the airway [9]

\begin{tabular}{ll}
\hline Airway mucin & \\
\hline $\begin{array}{l}\text { Membrane } \\
\text { tethered }\end{array}$ & $\begin{array}{l}\text { Gel- } \\
\text { forming }\end{array}$ \\
\hline MUC1 & MUC2 \\
MUC3A/B & MUC5AC \\
MUC4 & MUC5B \\
MUC11 & MUC6 \\
MUC13 & MUC7 \\
MUC15 & MUC8 \\
MUC16 & \\
MUC20 & MUC19 \\
MUC21 & \\
\hline
\end{tabular}




\section{Regulation of airway mucus secretion}

Mucin macromolecules in secretory cells (i.e. goblet cells) form secretory granules or vesicles and undergo a multi-step process of exocytic secretion, via intercompartmental vesicular trafficking. They progress from the ER, where they are synthesized, to the cis-Golgi, where they undergo core glycosylation; then through the Golgi, where they undergo further post-translational processing and sorting; and finally from the trans-Golgi to the cell surface. The secretory granules move from the trans-Golgi region to the cell periphery along microtubules and then along actin filaments. Only a few of the proteins that regulate the secretory process in airway goblet cells have been identified. Rab GTPases regulate the transition from microtubules to actin filaments. SNARE proteins, including vesicular-associated membrane protein 8 (VAMP8), regulate mucin granule exocytosis [31]. Deletion of Munc 13-2, a priming protein for mucin granule exocytosis that is activated by diacylglycerol during agonist stimulation, affects tonic mucin secretion in mouse airways [32]. Synaptotagmin 2, a low-affinity $\mathrm{Ca}^{2+}$ sensor, mediates acute agonist-stimulated mucin secretion in mouse airway goblet cells [33]. Myristoylated, alanine-rich C-kinase substrate (MARCKS) protein regulates mucin granule release via linking of mucin granules to the contractile cytoskeleton; the activity of MARCKS is regulated by protein kinase $\mathrm{C}$ and protein kinase G [34]. An inhibitory MARCKS peptide has been shown to reduce airway mucin secretion in a mouse model of asthma [35]. The identities and precise functions of many other molecular components of the goblet-cell secretory pathway are yet to be defined.

The secretion of mucus in the surface epithelium is controlled by a range of neurohumoral mediators, including tobacco smoke, $\mathrm{SO}_{2}, \mathrm{NH}_{3}$, leukotrienes $\mathrm{C}_{4}$ and $\mathrm{D}_{4}$, neutrophil elastase, histamine, platelet-activating factor (PAF), substance $\mathrm{P}$, reactive oxygen species, ATP, TNF- $\alpha$, NO, and extremes of $\mathrm{pH}$ [36]. Of these mediators ATP, possibly released into the airway lumen via mechanical stretching, is believed to be the most potent secretagogue of goblet cells. ATP and its analogue UTP cause rapid mucin-granule discharge by interacting directly with $\mathrm{P}_{2} \mathrm{Y}_{2}$ purinoceptors on airway goblet cells. They also stimulate $\mathrm{Cl}^{-}$and fluid secretion $[37,38]$, ciliary activity [39], and, importantly, mucociliary clearance [40].

Airway gland secretion is regulated by neural actions [36]. In humans, the submucosal glands are richly innervated by the parasympathetic, sympathetic, and nonadrenergic, noncholinergic (NANC) nervous systems [41]. Muscarinic, $\alpha$-adrenergic, $\beta$-adrenergic, and peptidergic receptors have all been observed on airway gland cells. Cholinergic agonists are the most potent releasers of mucus from the airway glands of humans and other mammals. In cats, $\alpha$-adrenergic agents and cholinergic agents stimulate approximately equal volume flow. $\beta$-Adrenergic agents induce lower volumes of secretions than either cholinergic or $\alpha$-adrenergic agents.

The intracellular second messengers of mucus secretion may involve inositol 1,4,5-trisphosphate $\left(\mathrm{IP}_{3}\right), \mathrm{DAG}$, and $\mathrm{Ca}^{2+}$. The PLC-specific inhibitor U73122 and loading of cells with the calcium chelator BAPTA inhibit agoniststimulated secretion $[42,43]$, whereas secretion is stimulated by:

1. the DAG-mimic PMA;

2. increasing intracellular $\mathrm{Ca}^{2+}$ with the ionophore ionomycin;

3. permeabilizing the cells into an extracellular $\mathrm{Ca}^{2+}$ EGTA-based buffer with streptolysin-O; and

4. applying $\mathrm{IP}_{3}$ to permeabilized cells [44].

Purinergic activation led to intracellular $\mathrm{Ca}^{2+}$ mobilization in human goblet cells, with a classic peak-and-plateau waveform. This mobilization was inhibited by U73122 or by BAPTA loading [45]. $\mathrm{Ca}^{2+}$ may regulate mucin granule exocytosis by activating actin filament disruption and remodeling (scinderin), priming (Munc13), and exocytic fusion (synaptotagmin) [44]. PLC is believed to be important in regulating mucin secretion. It is probable that multiple inputs (purinergic agonists and inflammatory mediators) converge via PLC to generate two cellular messengers, DAG and $\mathrm{Ca}^{2+}$, which then lead to exocytosis.

\section{Mucus hypersecretion in COPD airway}

Mucus hypersecretion is a prominent feature of COPD, manifested as increased sputum. Excess mucus has been associated with several pathological features of COPD:

- increased frequency and duration of infection;

- reduced lung function; and

- increased morbidity and mortality [46].

In the small airways of healthy individuals goblet cells are absent or sparse $[1,11]$ whereas in COPD patients elevated numbers of goblet cells (goblet cell metaplasia (GCM)) are found, with excessive mucus production [47]. The components of sputum are derived mainly from the central airways, with some contribution from the peripheral airways; however, over-production of mucus in the peripheral airways is the main cause of airflow obstruction in patients with COPD [48].

In COPD, airway mucus hypersecretion is often associated with changes to both location and profile of mucin expression in epithelium and submucosal glands. MUC1 is the first cloned and best-understood membrane-tethered mucin. Our unpublished data indicate that its extracellular part may be released into the airway lumen, because the level was increased in the BALF of mice with cigarette-smoke-induced COPD. Ishikawa et al. recently reported that the sputum level 
of KL-6 (MUC1) was significantly higher for COPD patients than for non-smokers, smokers, and prolonged coughers with normal lung function. The increases positively correlated with smoking history, aging, sputum macrophages, and eosinophils, and MUC1 was more prominently expressed in the bronchiolar and/or alveolar epithelium in COPD than in control lungs $[49,50]$. The predominant gel-forming mucins in the airways, MUC5AC and MUC5B, are present at lower levels in mucus from non-diseased airways [11]; in COPD airways their expression is much increased and their expression patterns altered compared with those of smokers and normal subjects. Studies analyzing the mucin components of airway mucus in COPD patients have revealed that MUC5AC and MUC5B are the major mucins in sputum, with MUC5B being the predominant form $[51,52 \cdot]$. Caramori et al. reported that in peripheral COPD airways COPD is associated with increased expression of MUC5B in the bronchiolar lumen and with increased MUC5AC in the bronchiolar epithelium [23]. In COPD patients, expression of MUC5AC is increased not only in surface epithelium but also in submucosal glands, and the increases are correlated with smoking history and inversely correlated with FEV1 (\% of predicted) [53]. MUC5B, normally expressed in the submucosal glands of the bronchials, was also present in the surface epithelium [52•]. The expression and location of MUC2, MUC4, and MUC6 in peripheral airways were not affected by smoking history or by COPD $[23,51,54]$. Other mucins have not been evaluated, but MUC7 and MUC8 are postulated to change during COPD. This assumption is made because cigarette smoke extract and LPS exposure induced MUC7 in human airway epithelial cells in vitro and in mouse cells in vivo [55], and because MUC8 was induced in airway epithelial cells by highmobility-group box-1 protein (HMGB1), a recently-identified pro-inflammatory mediator in a variety of inflammatory diseases [56].

In addition to the altered expression profile and increased synthesis of mucins, COPD airway mucus is usually dehydrated and more viscous, impeding mucus clearance. Recent studies suggest that the dehydrated mucus is probably the result of defects in activity or expression of CFTR, aquaporins, and other ion channels, leading to reduced ion and water secretion. CFTR functions both as a $\mathrm{Cl}^{-}$channel and as an important anti-inflammatory molecule [57]. Moreover, CFTR can mediate secretion of bicarbonate $\left(\mathrm{HCO}_{3}{ }^{-}\right)$, which is believed to enhance mucin swelling and hydration by reducing $\mathrm{Ca}^{2+}$ cross-linking in mucins, thereby reducing mucus viscosity and probably increasing its transportability [58]. Consequently, mutations in the CFTR gene are associated with mucus dehydration and airway inflammation, as seen in cystic fibrosis (CF). Cigarette smoke exposure rapidly impairs CFTR function by internalizing CFTR, leading to ASL dehydration. This promotes mucus stasis and failure of mucus clearance, leaving smokers at risk of developing chronic bronchitis (CB) [59]. $\mathrm{AQP}_{5}$ may affect mucus secretion by regulating fluid and mucin secretion [60]. Wang and associates [61] showed that airway expression of $\mathrm{AQP}_{5}$ was reduced in COPD patients compared with control subjects. Attenuated expression of $\mathrm{AQP}_{5}$ was related to severity of airflow obstruction and negatively correlated with expression of MUC5AC in the airway epithelium and of mucins in the submucosal glands. Chen et al. [62] found that the $\mathrm{AQP}_{5}$ gene could negatively regulate expression of the MUC5AC gene and proteins in the human airway submucosal gland-cell line SPC-A1.

\section{Function of mucins in COPD airway}

The general functions of mucins

Normally mucus floats like a raft above the cilia, capturing foreign bodies including microbes, particles, inflammatory cells, and cell debris by means of its gel-like structure and adhesive properties, and transporting them to locations where they can be expelled from the body via ciliary beating. The mucus layer may also provide a physical barrier to the epithelium against microorganisms and insoluble material, thereby maintaining the local molecular environment's hydration, ionic composition and concentration, and accessibility to macromolecules. The best-known function of mucus is this first innate defense of the respiratory tract [63]. The function of mucus is believed to be primarily conferred by mucins. In addition to defending the respiratory tract, functions of those mucins that have been described include [15]: capturing, holding, and releasing biologicallyactive molecules; signal transduction; regulation of inflammation and immune responses; and regulation of differentiation and proliferation.

Mucins have been shown to capture, hold, and release biologically active molecules, including cytokines, growth factor, and trefoil factors (TFFs). [15, 64]. Via these molecules, mucins may participate in regulation of inflammation and immune responses, and regulation of the repair of the injured airway. Besides capturing inflammatory cells, mucins have been found to capture interleukins, including IL-1, IL-4, IL6 , and IL-7, by means of interactions with the specific lectin moieties on these molecules $[15,64]$. Thus, mucins may enable inflammatory mediators and effectors to interact with pathogens, enabling resolution of inflammation. TFFs are expressed by most mucin-producing epithelia, including those of the respiratory tract. They bind to mucins, interact with them $[65,66]$ and regulating mucus viscosity [67], and via these actions may enhance the protective capability of the mucosal defense barrier. Studies of trefoil peptides in gastrointestinal epithelial cells found TFFs can enhance cell migration in vitro 
and promote epithelial restitution and mucosal repair in vivo $[68,69]$. In a murine asthma model it was discovered that trans-differentiating Clara cells express TFF1, which is stored in a subset of secretory granules [70]. Royce et al. reported that TFF2 regulates airway remodeling in animals models of asthma: TFF2-deficient mice developed asthma and had increased goblet-cell hyperplasia and sub-epithelial collagen layer thickness [71]. Lung transcript profiling of mice identified TFF2 as one of the candidate genes determining lung function [72]. Oertell and colleagues revealed that human recombinant TFF2 and TFF3 both stimulate migration of human airway epithelial cells in chemotactic and two-dimensional wound repair assays, either alone or in concert with EGF [73]. TFF3 was shown to promote airway epithelial ciliated cell differentiation, and induced expression of TFF3 was associated with differentiation of in-vivo humanized tracheal xenograft and in-vitro air-liquid-interface culture models. Furthermore, exogenous TFF3 promoted differentiation of ciliated cells in an EGF-receptordependent manner [74]. In a recent study, Wiede and associates found TFF3, but not TFF1 and TFF2, in airway mucosa and in the sputum of subjects with chronic bronchitis [75]. Reduced lung TFF3 mRNA expression was found in rats with COPD induced by passive smoking and LPS [76]. The function of TFFs in normal airways and in the repair of injured COPD epithelium is unknown.

Descriptions of mucins' functions in mediating signal transduction and in regulating differentiation and proliferation are mostly derived from studies of cancerous cells, with some already proved to apply to individual mucins in the airway epithelium. Below we summarize the known functions of the best-characterized airway mucins.

\section{Membrane-tethered mucins}

Of the membrane-tethered mucins MUCs 1, 4, 11, 15, 16, and 20 which have been identified in the lung, MUC1, MUC4, and MUC16 are the main three produced and released by airway surface-epithelial cells [77]. Understanding of the functions of MUC4 and MUC16 is still limited. MUC4 is broadly expressed in the small intestine, colon, stomach, cervix, and lung [78]. It is an inter-membrane ligand for ErbB2 [79]: binding of MUC4 to ErbB2 may block access of ErbB2 to its soluble ligands, thereby affecting regulation of cell proliferation and growth. In COPD the airway epithelium is chronically exposed to neutrophil elastase, a highly inflammatory protease released by infiltrated neutrophils. Neutrophil elastase has been shown to upregulate MUC4 mRNA and protein expression in normal human bronchial epithelial cells in vitro [80], suggesting MUC4 may affect lung inflammation. MUC16 has been mostly studied in ovarian cancer cells, and is also expressed in normal airway epithelium and submucosal gland cells [19]. The MUC16 (CA-125) blood level of COPD patients is significantly higher than that of control subjects, and is correlated with systolic pulmonary artery pressure [81]. The function of MUC16 in the airway is unknown.

MUC1 is the first cloned and best-understood mucin. MUC1 is expressed on the surface of most epithelial cells and some hematopoietic cells [82, 83]. It is a type I transmembrane protein with three domains: a highly glycosylated large extracellular (EC) domain made up of 25 to 125 twentyamino-acid tandem repeats, a hydrophobic transmembrane (TM) domain, and a cytoplasmic tail (CT) [82]. The glycosylated tandem repeat of MUC1 is an extended rodlike structure that can extend 200-500 $\mathrm{nm}$ above the cell surface. Both anti-adhesive and adhesive properties of MUC1 have been proposed on the basis of this large, extended conformation of the EC domain and the sialyl Lewis ${ }^{\mathrm{x}}$ and sialyl Lewis ${ }^{\mathrm{a}}$ carbohydrate found on it. MUC1 may also adhere, with ICAM-1, on endothelial cells and antigenpresenting dendritic cells (APC), facilitating tumor-cell metastasis or promoting T-cell and APC interaction [82]. The CT domain of MUC1 contains functional binding sites for numerous signaling molecules, including c-Src, ErbB family members, GSK $3 \beta$, PKC $\delta, \beta$-catenin, Grb-2, p53, p120 catenin, HSP70, and HSP90, and can be phosphorylated in response to a variety of extracellular stimulations, suggesting an important function of MUC1 CT in signal transduction [25, 84].

It has been suggested MUC1 is an oncoprotein because functions which include:

1. stimulating cell proliferation via beta-catenin, ErbB and $\mathrm{ER} \alpha$-dependent mechanisms;

2. facilitating cell survival via regulation of FOXO3a and p53 [25];

3. facilitating PyV MT-1 and Wnt-1-mediated oncogenesis [85]; and

4. facilitating tumor metastasis by interacting with endothelial intercellular adhesive molecule-1 (ICAM-1) [86].

Interaction with $\beta$-catenin and nuclear translocation of MUC1 CT initiates epithelial-to-mesenchymal transition (EMT) of pancreatic cancer cells, resulting in increased invasiveness and metastasis [87]. The secreted form of MUC1 (shed MUC1) seems also to be required for EMT [87, 88].

Investigating the function of MUC1 in the airway, our research group revealed that both hamster Muc1 and human MUC1 can provide a binding site on cells for Pseudomonas aeruginosa (PA), via interaction with the flagellin [89-91]. Binding of PA or flagellin to Muc1 induces tyrosine phosphorylation on the $\mathrm{CT}$ domain of MUC1 and resulting activation of ERK2 [84]. Later, using Muc1 null mice $\left(\mathrm{Mucl}^{-/}\right)$, we found airway challenge from either PA or its major pathogenic protein flagellin caused exaggerated lung inflammation for $\mathrm{Mucl}^{-/-}$mice compared with that for Mucl wild-type mice $\left(\mathrm{Mucl}^{+/+}\right)$, indicating that Muc1 
has an anti-inflammatory effect on airway PA infection, probably via interference with TLR5-mediated signaling [92••]. In HEK193 cells simultaneously over-expressing MUC1 and TLR5, we revealed that the mechanism of the inhibitory function of MUC1 in TLR5 signaling involves its association with TLR5, with subsequent inhibition of MyD88 recruitment to TLR5 in response to inflammatory stimulus [93]. In addition, we found neutraphil elastase can up-regulate MUC1 via a signaling pathway involving $\mathrm{PKC} \delta \rightarrow$ dual oxidase $1 \rightarrow$ reactive oxygen species $\rightarrow$ TNF- $\alpha$-converting enzyme $\rightarrow$ TNF- $\alpha \rightarrow$ TNFR $1 \rightarrow$ ERK2 $\rightarrow$ Sp1 $[94,95]$. After PA infection, Muc1 levels in the lungs of $\mathrm{Mucl}^{+/+}$mice steadily increased. The inflammatory responses of $\mathrm{TNFR}^{-/-}$mice were similar to those of $\mathrm{Mucl}^{-/-}$ mice. After PA infection, both $\mathrm{Muc}^{-/-}$mice and TNFRknockout mice $\left(\mathrm{TNFR}^{-/}\right.$) failed to up-regulate Muc1 and failed to resolve PA-induced inflammation [96]. These results indicate that TNF- $\alpha$ production is required for PAinduced Muc1 up-regulation: during airway infection, the feedback loop involving TNF- $\alpha$ (pro-inflammatory) and Muc1 (anti-inflammatory) is crucial for resolution of inflammation. As well as TLR5-mediated inflammation during PA infection or inhalation of flagellin, we found Muc1 also inhibits other TLR signaling (TLR2, 3, 4, 7, and 9) [97], and suppresses non-typeable Hemophilus influenzae [98] and respiratory syncytial virus-induced [99] airway inflammation, suggesting that MUC1 and Muc1 greatly affect infection and inflammation of the airway by various pathogenic bacteria and viruses.

It has been shown that MUC1 can be shed by means of proteolytic cleavage, both spontaneously and upon stimulation from, for example, TNF- $\alpha$ and PMA [100]. Proteases responsible for MUC1 shedding include neutrophil elastase [101, 102], TACE [100], MT1 MMP [103], MMP-14 [104], and gamma-secretase [105]. The function of MUC1 shedding is not fully understood. It has been suggested that shed MUC1, and possibly other membrane-tethered mucins, may form a gel in the immediate vicinity of the apical cell surface, probably serving as a protective barrier against invading pathogens and chemicals [24]. How and when membrane glycoproteins are cleaved is largely unknown, and are important questions to address in the context of airway infection and inflammation. Given the ability of the MUC1 ectodomain to bind invading bacteria $[89,91,104]$, it is possible that shed MUC1 may serve as a decoy receptor [104], preventing direct interaction of bacteria with the epithelial cell surface and facilitating bacterial clearance during infection. CF mice had mucus accumulation in the small intestine, which was not the result of Muc2, Muc3, and Muc5ac: protein expression of these mucins was similar, whereas there was a moderate increase in Muc1 protein [106]. Making CF mice Muc1 deficient $\left(\mathrm{CF} / \mathrm{Mucl}^{-/-}\right.$mice) prevented mucus accumulation, and these mice survived better on solid food [106]. Shed
Muc1 may therefore form part of mucus and contribute to mucus obstructions. In addition, accumulating evidence indicates shed MUC1 may also suppress immune responses by:

1. affecting leukocyte motility;

2. providing an impenetrable barrier for immune effector cells, thereby preventing an anti-tumor or anti-bacterial response;

3. inactivating immune effector cells via receptor-ligand interactions; and

4. sequestering cytokines (i.e. transforming growth factor (TGF)- $\alpha$ and TGF- $\beta$ ) or other compounds that suppress immune response.

Besides its predominant expression on epithelial cells, MUC1 is also expressed by subsets of naïve and activated T cells (CD4+, CD8+, Th17) [83, 107-110], dendritic cells [110, 111], monocytes [112], and macrophages (unpublished results). In immune cells of Muc1-deficient mice, MUC1 causes defects in T cell development and in natural killer and dendritic cells [82]. Dendritic cells lacking expression of Muc1 were constitutively activated and were more responsive to TLR signaling [113]. MUC1 inhibited development of myeloid-derived suppressor cells (MDSCs) from bone marrow (BM) progenitor cells, via regulation of beta-catenin stability [114].

In conclusion, MUC1 expression in the airway may greatly affect mucociliary clearance, regulation of immune response, and lung inflammation resolution. The function of MUC1 in COPD airway disease is unknown. Because MUC1 expression increases in COPD lungs, we assume over-expression of MUC1 may contribute to COPD lung pathology in the following ways [49]:

1. causing immunosuppression in the systemic and lung immune system via its EC and CT domain;

2. promoting airway remodeling and mucus differentiation, via its action in causing EMT;

3. masking bacteria, helping them escape killing by immune cells;

4. participating in mucus components, or acting as a tether for mucus gel, thus contributing to mucus obstruction [106]; and

5. disrupting intra-epithelial adhesion via c-Src and GSK $3 \beta$ dependent interaction with $\beta$-catenin [115].

These hypotheses must be proved in future studies.

Secreted mucins

As described above, there are four main secreted mucins in the lung: MUC2, MUC5AC, MUC5B, and MUC19. MUC2 is the main intestinal mucin and is expressed by the goblet cells of the colon and small intestine, although expression may be detected in diseased lungs of humans and rats [116]. Muc2knockout mice have defects of goblet cell development in the colon, with absence of the protective colonic mucus layer 
leading to colonic inflammation and to spontaneous development of colitis [117] and of colorectal cancer [118]. The antiinflammatory and tumor-suppressive functions of MUC2 in the colon are not fully understood. MUC2 is expressed in the lungs of humans with chronic bronchitis and cystic fibrosis [119], but immunoassay and proteomics analysis of normal and COPD sputum indicate that it may not be a major component of mucins $[54,77,120]$. MUC19, the main salivary glandular mucin, has also been identified in the tracheolarynx [121] and found to be expressed in mouse lungs [122]. The functions of MUC2 and MUC19 in the lung are unknown.

MUC5AC and MUC5B are the main components of gelforming mucins in normal airways and are believed to contribute to both the defensive barrier function and the rheology of airway mucus. Their biochemistry was recently reviewed by Thornton et al. [123]. MUC5AC has been shown to be the goblet cell mucin [124] and MUC5B the submucosal gland mucin [125]. MUC5AC is widely used as a marker for goblet cell metaplasia [126]. MUC5B is the main mucin type in the apical secretions of air-liquid-interface-cultured NHBE cells and in induced sputum [77]. MUC5AC is up-regulated in a variety of pathologies, including COPD [53, 127]. MUC5AC expression is increased in the bronchial submucosal glands of stable COPD patients [53]. During allergic airway inflammation MUC5AC expression greatly increases, whereas MUC5B expression remains constant [122, 128, 129]. By use of the western blotting assay, Thorton et al. measured levels of MUC2, MUC5AC, and the different glycoforms of MUC5B mucin directly in sputum $[14,51]$. Comparing secretions from normal subjects and from individuals with asthma, $\mathrm{CF}$, and COPD, they found more MUC5B mucin, particularly the lowcharge form, in $\mathrm{CF}$ and COPD sputum with possible infection. Therefore, MUC5AC is believed to be more related to asthma $[128,130,131]$ and MUC5B to COPD [52•]. A significant association was found between the overall distribution of MUC5AC variable number tandem repeat (VNTR) length and $\mathrm{CF}$ lung disease severity; there was also a strong association of the $6.4 \mathrm{~kb}$ HinfI VNTR fragment with severity of lung disease [127]. It is suggested that MUC5AC may function by facilitating ciliary clearance of mucus, whereas MUC5B may form the basis of a gel to facilitate clearance of specific pathogens or other irritants. Recently, an MUC5B-promoter polymorphism has been associated with pulmonary fibrosis [132]. The comprehensive functions of MUC5AC and MUC5B in COPD are yet to be discovered; it is expected this will happen very soon now that knockout mice are available.

\section{Regulation of mucus hypersecretion related to COPD}

Growing evidence indicates that mucus hypersecretion in COPD is probably induced by microbial products, airborne pollutants, and mediators of inflammation. Both virus and bacterial products have been shown to directly up-regulate mucin expression [133]. Instillation of lipopolysaccharide (LPS) and inhalation of sulfur dioxide, ozone, cigarette smoke, and acrolein can all induce GCM and up-regulate MUC5AC expression in rat or mouse airway epithelia [30, 134-138]. Exposure to these airway irritants leads to GCM and to neutrophilia inflammation in animals. It is noteworthy that this associated inflammation also seems to mediate development of GCM. Instillation of neutrophil elastase stimulates bronchial GCM in hamsters and mice $[139,140]$. TH1 and TH2 cytokines shown to regulate mucin gene expression and GCM in vivo include IL-9 and IL-13 (the predominant TH2 cytokines), IL-1 $\beta$, tumor necrosis factor- $\alpha$ (TNF- $\alpha$ ), TGF- $\alpha$, IL- 6 , and IL-17 [141]. Downstream signaling mechanisms of mucin upregulation and GCM probably involve epidermal growth factor receptor (EGF-R), STAT6, FOXA2, SAM-domain-containing prostate-derived Ets factor (SPDEF), and NF-kappaB [141]. In addition, activation of hypoxia-inducible factor-1 signaling was recently found to contribute to the mechanism of GCM in COPD patients [142]. Notch signaling is critical to negative regulation of Muc5ac expression and GCM in postnatal mouse lungs [143]. Of these known signaling mechanisms for mucin and GCM regulation, EGF-R and Th2 cytokine pathways may have the greatest potential for inhibiting excessive mucus production [144].

\section{Management of COPD airway mucus}

Mucus retention in COPD is associated with disease exacerbation [145], accelerated decline in $\mathrm{FEV}_{1}$ [146], and inflammatory cell infiltration [145]. Mucus retention usually results from a combination of hypersecretion and impaired clearance. Therefore, mucoactive medications used to enhance secretion removal or reduce hypersecretion are important in managing COPD. Mucoactive agents are classified, on the basis of their pharmacological functions, as [36]:

1. expectorants, e.g. guaifenesin, which induces a "vagal gastric" reflex, and hypertonic saline and mannitol, which stimulate epithelial water secretion;

2. ion-transport modifiers, e.g. CPX, genistein, and phenylbutyrate, CFTR activators, which improve the ability of abnormal CFTR to transport $\mathrm{Cl}^{-}$, and UTP, which increases non-CFTR $\mathrm{Cl}^{-}$and water transport;

3. mucolytics, including $N$-acetylcysteine (NAC), heparin, and low-molecular-weight dextran, which disrupt mucus or sputum polymers;

4. mucokinetics, e.g. beta-agonists and surfactants, which increase clearance of sputum in coughs; and

5. mucoregulatory agents, including atropine and glucocorticosteroids, which reduce mucin production and/or secretion. 
The efficacy of mucoactive agents for COPD management is shown in a well-summarized systemic review by Poole and Black [147]. This review included 26 randomized, placebo-controlled studies recruiting 7,335 participants with COPD. Their data showed that treatment with mucolytics for at least two months significantly reduced the occurrence of exacerbation, and suggested longer-term treatment with mucolytics might achieve even better results.

Of the mucoactive agents, NAC is the most commonlyused and cost-effective. Several clinical studies found that administration of NAC to COPD patients reduced acute exacerbation. The exception is the BRONCHUS study [148], in which significant reduction in the occurrence of exacerbation by use of NAC $600 \mathrm{mg}$ day $^{-1}$ was shown only for patients without concomitant use of inhaled corticosteroids. According to studies by Gerrits [149] and by Zuin et al. [150], the effectiveness of NAC in reducing risk of COPD exacerbation could be dose-dependent. Therefore, a higher dose of NAC (1200 mg day $\left.{ }^{-1}\right)$ was used in our PANTHEON study trial [151].

Carbocysteine is an analogue of NAC, and is more metabolically stable and lower in cost. Our recent clinical trial revealed that oral administration of $1,500 \mathrm{mg} \mathrm{day}^{-1}$ for one year resulted in significant reduction of the annual occurrence of exacerbation for COPD patients (risk ratio 0.75 (95\% CI $0.62-0.92, p=0.004))[6 \bullet \cdot$, irrespective of disease severity, smoking status, and concomitant use of inhaled corticosteroids. Quality of life, determined by use of St George's Respiratory Questionnaire (SGRQ), also improved significantly. The efficacy of carbocysteine may be attributable to its mucolytic, antiinflammatory, and anti-oxidation activity. First, carbocysteine improves removal of mucus via activating $\mathrm{Cl}^{-}$conductance in human respiratory cells, correcting the balance between sialo and fuco-mucins, and modulating $\mathrm{Cl}^{-}$and water secretion. Second, carbocysteine is able to stimulate secretion of glutathione (GSH) [152]. A promoter of mucolysis because of its ability to cleave disulfide bonds in mucus, GSH is also one of the most important defense mechanisms against oxidative stress in COPD. Third, it is possible that carbocysteine performs this function via inhibiting mucin production, reducing MUC5AC production and inflammation induced by influenza viruses $\mathrm{A}$ and $\mathrm{B}$ and by respiratory syncytial virus [133].

\section{Conclusions}

Mucus hypersecretion is an important pathological feature of COPD airway disease. Knowledge of mucus and mucin biology, and of the mechanisms of their regulation, has greatly increased. Understanding the function of mucins in COPD airway disease may result in development of novel therapeutic approaches for COPD; the lack of current knowledge in this area justifies more studies.
Acknowledgments This work was supported by Changjiang Scholars and Innovative Research Team in University grant (IRT0961), National Key Technology R\&D Program of the 12th National Five-year Development Plan (2012BAI05B01), Guangdong Natural Science Foundation team grant (1035101200300000), and Guangzhou Department of Education Yangcheng Scholarship (10A058S).

Conflict of Interest Wenju $\mathrm{Lu}$ declares that she has no conflict of interest.

Jinping Zheng has received honoraria from Hainan Zambon Pharmaceuticals and has been a consultant to and served on speakers' bureaus for AstraZeneca, GlaxoSmithKline, and Boehringer-Ingelheim.

\section{References}

Papers of particular interest, published recently, have been highlighted as:

- Of importance

-. Of major importance

1. Jeffery PK. Structural and inflammatory changes in COPD: a comparison with asthma. Thorax. 1998;53(2):129-36.

2. Chung KF. Cytokines in chronic obstructive pulmonary disease. Eur Respir J Suppl. 2001;34:50s-9s.

3. Maestrelli P, Saetta M, Mapp CE, Fabbri LM. Remodeling in response to infection and injury. Airway inflammation and hypersecretion of mucus in smoking subjects with chronic obstructive pulmonary disease. Am J Respir Crit Care Med. 2001;164(10 Pt 2):S76-80.

4. Prescott E, Lange P, Vestbo J. Chronic mucus hypersecretion in COPD and death from pulmonary infection. Eur Respir J. 1995;8(8):1333-8.

5. Rogers DF. Mucoactive drugs for asthma and COPD: any place in therapy? Expert Opin Investig Drugs. 2002;11(1):15-35.

6. • Zheng JP, Kang J, Huang SG, et al. Effect of carbocisteine on acute exacerbation of chronic obstructive pulmonary disease (PEACE Study): a randomised placebo-controlled study. Lancet. 2008;371(9629):2013-8. This study identified carbocisteine is a cost-effective medication preventing acute exacerbation in COPD patients.

7. Rogers DF. The airway goblet cell. Int J Biochem Cell Biol. 2003;35(1):1-6.

8. Jacquot J, Hayem A, Galabert C. Functions of proteins and lipids in airway secretions. Eur Respir J. 1992;5(3):343-58.

9. Voynow JA, Rubin BK. Mucins, mucus, and sputum. Chest. 2009;135(2):505-12.

10. Fahy JV, Dickey BF. Airway mucus function and dysfunction. N Engl J Med. 2010;363(23):2233-47.

11. Williams OW, Sharafkhaneh A, Kim V, Dickey BF, Evans CM. Airway mucus: from production to secretion. Am J Respir Cell Mol Biol. 2006;34(5):527-36.

12. Rose MC, Voynow JA. Respiratory tract mucin genes and mucin glycoproteins in health and disease. Physiol Rev. 2006;86(1): 245-78.

13. Wanner A, Salathe M, O'Riordan TG. Mucociliary clearance in the airways. Am J Respir Crit Care Med. 1996;154(6 Pt 1):1868-902.

14. Thornton DJ, Sheehan JK. From mucins to mucus: toward a more coherent understanding of this essential barrier. Proc Am Thorac Soc. 2004;1(1):54-61.

15. Hollingsworth MA, Swanson BJ. Mucins in cancer: protection and control of the cell surface. Nat Rev Cancer. 2004;4(1):45-60. 
16. Stonebraker JR, Wagner D, Lefensty RW, et al. Glycocalyx restricts adenoviral vector access to apical receptors expressed on respiratory epithelium in vitro and in vivo: role for tethered mucins as barriers to lumenal infection. J Virol. 2004;78(24):13755-68.

17. Kim KC. Role of epithelial mucins during airway infection. Pulm Pharmacol Ther. 2011.

18. Bernacki SH, Nelson AL, Abdullah L, et al. Mucin gene expression during differentiation of human airway epithelia in vitro. Muc4 and muc5b are strongly induced. Am J Respir Cell Mol Biol. 1999;20(4):595-604.

19. Davies JR, Kirkham S, Svitacheva N, Thornton DJ, Carlstedt I. MUC16 is produced in tracheal surface epithelium and submucosal glands and is present in secretions from normal human airway and cultured bronchial epithelial cells. Int J Biochem Cell Biol. 2007;39(10):1943-54.

20. Itoh Y, Kamata-Sakurai M, Denda-Nagai K, et al. Identification and expression of human epiglycanin/MUC21: a novel transmembrane mucin. Glycobiology. 2008;18(1):74-83.

21. Copin MC, Buisine MP, Devisme L, et al. Normal respiratory mucosa, precursor lesions and lung carcinomas: differential expression of human mucin genes. Front Biosci. 2001;6:D1264-1275.

22. Dohrman A, Tsuda T, Escudier E, et al. Distribution of lysozyme and mucin (MUC2 and MUC3) mRNA in human bronchus. Exp Lung Res. 1994;20(4):367-80.

23. Caramori G, Di Gregorio C, Carlstedt I, et al. Mucin expression in peripheral airways of patients with chronic obstructive pulmonary disease. Histopathology. 2004;45(5):477-84.

24. Sheehan JK, Kesimer M, Pickles R. Innate immunity and mucus structure and function. Novartis Found Symp. 2006;279:155-66. discussion 167-159, 216-159.

25. Hattrup CL, Gendler SJ. Structure and function of the cell surface (tethered) mucins. Annu Rev Physiol. 2008;70:431-57.

26. Jarrard JA, Linnoila RI, Lee H, Steinberg SM, Witschi H, Szabo E. MUC1 is a novel marker for the type II pneumocyte lineage during lung carcinogenesis. Cancer Res. 1998;58(23):5582-9.

27. Umehara T, Kato K, Park YS, Lillehoj EP, Kawauchi H, Kim KC. Prevention of lung injury by Muc1 mucin in a mouse model of repetitive Pseudomonas aeruginosa infection. Inflamm Res. 2012.

28. Zhu L, Lee P, Yu D, Tao S, Chen Y. Cloning and characterization of human MUC19 gene. Am J Respir Cell Mol Biol. 2011;45(2): 348-58.

29. Chen Y, Zhao YH, Kalaslavadi TB, et al. Genome-wide search and identification of a novel gel-forming mucin MUC19/Muc19 in glandular tissues. Am J Respir Cell Mol Biol. 2004;30(2): $155-65$.

30. Leikauf GD, Borchers MT, Prows DR, Simpson LG. Mucin apoprotein expression in COPD. Chest. 2002;121(5 Suppl): $166 \mathrm{~S}-82 \mathrm{~S}$.

31. Jones LC, Moussa L, Fulcher ML, et al. VAMP8 is a vesicle SNARE that regulates mucin secretion in airway goblet cells. J Physiol. 2012;590(Pt 3):545-62.

32. Zhu Y, Ehre C, Abdullah LH, et al. Munc13-2-/- baseline secretion defect reveals source of oligomeric mucins in mouse airways. J Physiol. 2008;586(7):1977-92.

33. Tuvim MJ, Mospan AR, Burns KA, et al. Synaptotagmin 2 couples mucin granule exocytosis to $\mathrm{Ca} 2+$ signaling from endoplasmic reticulum. J Biol Chem. 2009;284(15):9781-7.

34. Li Y, Martin LD, Spizz G, Adler KB. MARCKS protein is a key molecule regulating mucin secretion by human airway epithelial cells in vitro. J Biol Chem. 2001;276(44):40982-90.

35. Singer M, Martin LD, Vargaftig BB, et al. A MARCKS-related peptide blocks mucus hypersecretion in a mouse model of asthma. Nat Med. 2004;10(2):193-6.

36. Rubin BK, Schans CPvd. Therapy for mucus-clearance disorders. New York: Marcel Dekker; 2004.
37. Boucher RC. Human airway ion transport. Part one. Am J Respir Crit Care Med. 1994;150(1):271-81.

38. Boucher RC. Human airway ion transport. Part two. Am J Respir Crit Care Med. 1994;150(2):581-93.

39. Salathe M. Regulation of mammalian ciliary beating. Annu Rev Physiol. 2007;69:401-22.

40. Olivier KN, Bennett WD, Hohneker KW, et al. Acute safety and effects on mucociliary clearance of aerosolized uridine 5'-triphosphate $+/$ - amiloride in normal human adults. Am J Respir Crit Care Med. 1996;154(1):217-23.

41. Rogers DF. Pharmacological regulation of the neuronal control of airway mucus secretion. Curr Opin Pharmacol. 2002;2(3):249-55.

42. Kemp PA, Sugar RA, Jackson AD. Nucleotide-mediated mucin secretion from differentiated human bronchial epithelial cells. Am J Respir Cell Mol Biol. 2004;31(4):446-55.

43. Abdullah LH, Davis CW. Regulation of airway goblet cell mucin secretion by tyrosine phosphorylation signaling pathways. Am J Physiol Lung Cell Mol Physiol. 2007;293(3):L591-599.

44. Davis CW, Dickey BF. Regulated airway goblet cell mucin secretion. Annu Rev Physiol. 2008;70:487-512.

45. Rossi AH, Salmon WC, Chua M, Davis CW. Calcium signaling in human airway goblet cells following purinergic activation. Am J Physiol Lung Cell Mol Physiol. 2007;292(1):L92-98.

46. Vestbo J. Epidemiological studies in mucus hypersecretion. Novartis Found Symp. 2002;248:3-12. discussion 12-19, 277-282.

47. Saetta M, Turato G, Baraldo S, et al. Goblet cell hyperplasia and epithelial inflammation in peripheral airways of smokers with both symptoms of chronic bronchitis and chronic airflow limitation. Am J Respir Crit Care Med. 2000;161(3 Pt 1):1016-21.

48. Alexis NE, Hu SC, Zeman K, Alter T, Bennett WD. Induced sputum derives from the central airways: confirmation using a radiolabeled aerosol bolus delivery technique. Am J Respir Crit Care Med. 2001;164(10 Pt 1):1964-70.

49. Ishikawa N, Mazur W, Toljamo T, et al. Ageing and long-term smoking affects KL-6 levels in the lung, induced sputum and plasma. BMC Pulm Med. 2011;11:22.

50. Ishikawa N, Hattori N, Tanaka S, et al. Levels of surfactant proteins A and D and KL-6 are elevated in the induced sputum of chronic obstructive pulmonary disease patients: a sequential sputum analysis. Respiration. 2011;82(1):10-8.

51. Kirkham S, Sheehan JK, Knight D, Richardson PS, Thornton DJ. Heterogeneity of airways mucus: variations in the amounts and glycoforms of the major oligomeric mucins MUC5AC and MUC5B. Biochem J. 2002;361(Pt 3):537-46.

52. • Kirkham S, Kolsum U, Rousseau K, Singh D, Vestbo J, Thornton DJ. MUC5B is the major mucin in the gel phase of sputum in chronic obstructive pulmonary disease. Am J Respir Crit Care Med. 2008;178(10):1033-9. This study found that MUC5AC was the predominant mucin in the sputum of smokers, whereas MUC5B, predominantly the lower-charged glycosylated form, was more abundant in the sputum from COPD patients.

53. Caramori G, Casolari P, Di Gregorio C, et al. MUC5AC expression is increased in bronchial submucosal glands of stable COPD patients. Histopathology. 2009;55(3):321-31.

54. Hovenberg HW, Davies JR, Herrmann A, Linden CJ, Carlstedt I. MUC5AC, but not MUC2, is a prominent mucin in respiratory secretions. Glycoconj J. 1996;13(5):839-47.

55. Fan H, Bobek LA. Regulation of human MUC7 Mucin gene expression by cigarette smoke extract or cigarette smoke and Pseudomonas aeruginosa lipopolysaccharide in human airway epithelial cells and in MUC7 transgenic mice. Open Respir Med J. 2010;4:63-70.

56. Kim DE, Min KJ, Kim JS, Kwon TK. High-mobility group box-1 protein induces mucin 8 expression through the activation of the JNK and PI3K/Akt signal pathways in human airway epithelial cells. Biochem Biophys Res Commun. 2012. 
57. Cohen TS, Prince A. Cystic fibrosis: a mucosal immunodeficiency syndrome. Nat Med. 2012;18(4):509-19.

58. Quinton PM. Role of epithelial HCO3(-) transport in mucin secretion: lessons from cystic fibrosis. Am J Physiol Cell Physiol. 2010;299(6): C1222-1233.

59. Clunes LA, Davies CM, Coakley RD, et al. Cigarette smoke exposure induces CFTR internalization and insolubility, leading to airway surface liquid dehydration. FASEB J. 2012;26(2): 533-45.

60. Wang $\mathrm{K}$, Wen $\mathrm{FQ}, \mathrm{Xu} \mathrm{D}$. Mucus hypersecretion in the airway. Chin Med J (Engl). 2008;121(7):649-52.

61. Wang K, Feng YL, Wen FQ, et al. Decreased expression of human aquaporin-5 correlated with mucus overproduction in airways of chronic obstructive pulmonary disease. Acta Pharmacol Sin. 2007;28(8):1166-74.

62. Chen Z, Wang X, Gao L, Bai L, Zhu R, Bai C. Regulation of MUC5AC mucin secretion by depletion of AQP5 in SPC-A1 cells. Biochem Biophys Res Commun. 2006;342(3):775-81.

63. Knowles MR, Boucher RC. Mucus clearance as a primary innate defense mechanism for mammalian airways. J Clin Invest. 2002;109(5):571-7.

64. Cebo C, Dambrouck T, Maes E, et al. Recombinant human interleukins IL-1alpha, IL-1beta, IL-4, IL-6, and IL-7 show different and specific calcium-independent carbohydrate-binding properties. J Biol Chem. 2001;276(8):5685-91.

65. Tomasetto C, Masson R, Linares JL, et al. pS2/TFF1 interacts directly with the VWFC cysteine-rich domains of mucins. Gastroenterology. 2000;118(1):70-80.

66. Kindon H, Pothoulakis C, Thim L, Lynch-Devaney K, Podolsky DK. Trefoil peptide protection of intestinal epithelial barrier function: cooperative interaction with mucin glycoprotein. Gastroenterology. 1995;109(2):516-23.

67. Thim L, Madsen F, Poulsen SS. Effect of trefoil factors on the viscoelastic properties of mucus gels. Eur J Clin Invest. 2002;32(7):519-27.

68. Podolsky DK. Healing the epithelium: solving the problem from two sides. J Gastroenterol. 1997;32(1):122-6.

69. Wong WM, Poulsom R, Wright NA. Trefoil peptides. Gut. 1999;44(6):890-5.

70. Kouznetsova I, Chwieralski CE, Balder R, et al. Induced trefoil factor family 1 expression by trans-differentiating Clara cells in a murine asthma model. Am J Respir Cell Mol Biol. 2007;36(3):286-95.

71. Royce SG, Lim C, Muljadi RC, Tang ML. Trefoil factor 2 regulates airway remodeling in animal models of asthma. J Asthma. 2011;48(7):653-9.

72. Ganguly K, Stoeger T, Wesselkamper SC, et al. Candidate genes controlling pulmonary function in mice: transcript profiling and predicted protein structure. Physiol Genomics. 2007;31(3):410-21.

73. Oertel M, Graness A, Thim L, Buhling F, Kalbacher H, Hoffmann W. Trefoil factor family-peptides promote migration of human bronchial epithelial cells: synergistic effect with epidermal growth factor. Am J Respir Cell Mol Biol. 2001;25(4):418-24.

74. LeSimple P, van Seuningen I, Buisine MP, et al. Trefoil factor family 3 peptide promotes human airway epithelial ciliated cell differentiation. Am J Respir Cell Mol Biol. 2007;36(3):296-303.

75. Wiede A, Jagla W, Welte T, Kohnlein T, Busk H, Hoffmann W. Localization of TFF3, a new mucus-associated peptide of the human respiratory tract. Am J Respir Crit Care Med. 1999;159(4 Pt 1):1330-5

76. Li YH, Zheng FJ, Huang Y, Zhong XG, Guo MZ. Synergistic anti-inflammatory effect of Radix Platycodon in combination with herbs for cleaning-heat and detoxification and its mechanism. Chin J Integr Med. 2011.

77. Kesimer M, Kirkham S, Pickles RJ, et al. Tracheobronchial airliquid interface cell culture: a model for innate mucosal defense of the upper airways? Am J Physiol Lung Cell Mol Physiol. 2009;296(1):L92-L100.

78. Gendler SJ, Spicer AP. Epithelial mucin genes. Annu Rev Physiol. 1995;57:607-34.

79. Carraway 3rd KL, Rossi EA, Komatsu M, et al. An intramembrane modulator of the ErbB2 receptor tyrosine kinase that potentiates neuregulin signaling. J Biol Chem. 1999;274(9): 5263-6.

80. Fischer BM, Cuellar JG, Diehl ML, et al. Neutrophil elastase increases MUC4 expression in normal human bronchial epithelial cells. Am J Physiol Lung Cell Mol Physiol. 2003;284(4): L671-679.

81. Yilmaz MB, Zorlu A, Dogan OT, Karahan O, Tandogan I, Akkurt I. Role of CA-125 in identification of right ventricular failure in chronic obstructive pulmonary disease. Clin Cardiol. 2011;34(4): 244-8.

82. Gendler SJ. MUC1, the renaissance molecule. J Mammary Gland Biol Neoplasia. 2001;6(3):339-53.

83. Chang JF, Zhao HL, Phillips J, Greenburg G. The epithelial mucin, MUC1, is expressed on resting $\mathrm{T}$ lymphocytes and can function as a negative regulator of $\mathrm{T}$ cell activation. Cell Immunol. 2000;201(2):83-8.

84. Lillehoj EP, Kim H, Chun EY, Kim KC. Pseudomonas aeruginosa stimulates phosphorylation of the airway epithelial membrane glycoprotein Muc1 and activates MAP kinase. Am J Physiol Lung Cell Mol Physiol. 2004;287(4):L809-815.

85. Schroeder JA, Adriance MC, Thompson MC, Camenisch TD, Gendler SJ. MUC1 alters beta-catenin-dependent tumor formation and promotes cellular invasion. Oncogene. 2003;22(9):1324-32.

86. Rahn JJ, Chow JW, Horne GJ, et al. MUC1 mediates transendothelial migration in vitro by ligating endothelial cell ICAM-1. Clin Exp Metastasis. 2005;22(6):475-83.

87. Roy LD, Sahraei M, Subramani DB, et al. MUC1 enhances invasiveness of pancreatic cancer cells by inducing epithelial to mesenchymal transition. Oncogene. 2011;30(12):1449-59.

88. Horn G, Gaziel A, Wreschner DH, Smorodinsky NI, Ehrlich M. ERK and PI3K regulate different aspects of the epithelial to mesenchymal transition of mammary tumor cells induced by truncated MUC1. Exp Cell Res. 2009;315(8):1490-504.

89. Lillehoj EP, Hyun SW, Kim BT, et al. Muc1 mucins on the cell surface are adhesion sites for Pseudomonas aeruginosa. Am J Physiol Lung Cell Mol Physiol. 2001;280(1):L181-187.

90. Lillehoj EP, Kim BT, Kim KC. Identification of Pseudomonas aeruginosa flagellin as an adhesin for Muc1 mucin. Am J Physiol Lung Cell Mol Physiol. 2002;282(4):L751-756.

91. Kato K, Lillehoj EP, Kai H, Kim KC. MUC1 expression by human airway epithelial cells mediates Pseudomonas aeruginosa adhesion. Front Biosci (Elite Ed). 2010;2:68-77.

92. •• Lu W, Hisatsune A, Koga T, et al. Cutting edge: enhanced pulmonary clearance of Pseudomonas aeruginosa by Muc1 knockout mice. J Immunol. 2006;176(7):3890-4. This study found that MUC1 and Mucl are important anti-inflammatory molecules which suppress pulmonary innate immunity during airway infection.

93. Kato K, Lillehoj EP, Park YS, et al. Membrane-tethered MUC1 mucin is phosphorylated by epidermal growth factor receptor in airway epithelial cells and associates with TLR5 to inhibit recruitment of MyD88. J Immunol. 2012;188(4):2014-22.

94. Kuwahara I, Lillehoj EP, Hisatsune A, et al. Neutrophil elastase stimulates MUC1 gene expression through increased Sp1 binding to the MUC1 promoter. Am J Physiol Lung Cell Mol Physiol. 2005;289(2):L355-362.

95. Koga T, Kuwahara I, Lillehoj EP, et al. TNF-alpha induces MUC1 gene transcription in lung epithelial cells: its signaling pathway and biological implication. Am J Physiol Lung Cell Mol Physiol. 2007;293(3):L693-701. 
96. Choi S, Park YS, Koga T, Treloar A, Kim KC. TNF-alpha is a key regulator of MUC1, an anti-inflammatory molecule, during airway Pseudomonas aeruginosa infection. Am J Respir Cell Mol Biol. 2011;44(2):255-60.

97. Ueno K, Koga T, Kato K, et al. MUC1 mucin is a negative regulator of toll-like receptor signaling. Am J Respir Cell Mol Biol. 2008;38(3):263-8.

98. Kyo Y, Kato K, Park YS, et al. Antiinflammatory role of MUC1 mucin during infection with nontypeable Haemophilus influenzae. Am J Respir Cell Mol Biol. 2012;46(2):149-56.

99. Li Y, Dinwiddie DL, Harrod KS, Jiang Y, Kim KC. Antiinflammatory effect of MUC1 during respiratory syncytial virus infection of lung epithelial cells in vitro. Am J Physiol Lung Cell Mol Physiol. 2010;298(4):L558-563.

100. Thathiah A, Blobel CP, Carson DD. Tumor necrosis factor-alpha converting enzyme/ADAM 17 mediates MUC1 shedding. J Biol Chem. 2003;278(5):3386-94.

101. Kim KC, Wasano K, Niles RM, Schuster JE, Stone PJ, Brody JS. Human neutrophil elastase releases cell surface mucins from primary cultures of hamster tracheal epithelial cells. Proc Natl Acad Sci U S A. 1987;84(24):9304-8.

102. Blalock TD, Spurr-Michaud SJ, Tisdale AS, Gipson IK. Release of membrane-associated mucins from ocular surface epithelia. Invest Ophthalmol Vis Sci. 2008;49(5):1864-71.

103. Thathiah A, Carson DD. MT1-MMP mediates MUC1 shedding independent of TACE/ADAM17. Biochem J. 2004;382(Pt 1): 363-73.

104. Linden SK, Sheng YH, Every AL, et al. MUC1 limits Helicobacter pylori infection both by steric hindrance and by acting as a releasable decoy. PLoS Pathog. 2009;5(10):e1000617.

105. Julian J, Dharmaraj N, Carson DD. MUC1 is a substrate for gamma-secretase. J Cell Biochem. 2009;108(4):802-15.

106. Parmley RR, Gendler SJ. Cystic fibrosis mice lacking Muc1 have reduced amounts of intestinal mucus. J Clin Invest. 1998;102(10): 1798-806.

107. Agrawal B, Krantz MJ, Parker J, Longenecker BM. Expression of MUC1 mucin on activated human T cells: implications for a role of MUC1 in normal immune regulation. Cancer Res. 1998;58(18): 4079-81.

108. Konowalchuk JD, Agrawal B. MUC1 mucin is expressed on human T-regulatory cells: function in both co-stimulation and co-inhibition. Cell Immunol. 2012;272(2):193-9.

109. Nishida A, Lau CW, Zhang M, et al. The membrane-bound mucin Muc1 regulates $\mathrm{T}$ helper 17-cell responses and colitis in mice. Gastroenterology. 2012;142(4):865-74. e862.

110. Wykes M, MacDonald KP, Tran M, et al. MUC1 epithelial mucin (CD227) is expressed by activated dendritic cells. J Leukoc Biol. 2002;72(4):692-701.

111. Cloosen S, Thio M, Vanclee A, et al. Mucin-1 is expressed on dendritic cells, both in vitro and in vivo. Int Immunol. 2004;16(11): 1561-71.

112. Leong CF, Raudhawati O, Cheong SK, Sivagengei K, Noor Hamidah H. Epithelial membrane antigen (EMA) or MUC1 expression in monocytes and monoblasts. Pathology. 2003;35(5): 422-7.

113. Williams MA, Bauer S, Lu W, et al. Deletion of the mucin-like molecule muc1 enhances dendritic cell activation in response to toll-like receptor ligands. J Innate Immun. 2010;2(2):123-43.

114. Poh TW, Bradley JM, Mukherjee P, Gendler SJ. Lack of Muc1regulated beta-catenin stability results in aberrant expansion of $\mathrm{CD} 11 \mathrm{~b}+\mathrm{Gr} 1+$ myeloid-derived suppressor cells from the bone marrow. Cancer Res. 2009;69(8):3554-62.

115. Li Y, Kuwahara H, Ren J, Wen G, Kufe D. The c-Src tyrosine kinase regulates signaling of the human DF3/MUC1 carcinomaassociated antigen with GSK3 beta and beta-catenin. J Biol Chem. 2001;276(9):6061-4.
116. Jany BH, Gallup MW, Yan PS, Gum JR, Kim YS, Basbaum CB. Human bronchus and intestine express the same mucin gene. J Clin Invest. 1991;87(1):77-82.

117. Van der Sluis M, De Koning BA, De Bruijn AC, et al. Muc2-deficient mice spontaneously develop colitis, indicating that MUC2 is critical for colonic protection. Gastroenterology. 2006;131(1):117-29.

118. Velcich A, Yang W, Heyer J, et al. Colorectal cancer in mice genetically deficient in the mucin Muc2. Science. 2002;295(5560): 1726-9.

119. Ohmori H, Dohrman AF, Gallup M, et al. Molecular cloning of the amino-terminal region of a rat MUC 2 mucin gene homologue. Evidence for expression in both intestine and airway. $\mathrm{J}$ Biol Chem. 1994;269(27):17833-40.

120. Thornton DJ, Carlstedt I, Howard M, Devine PL, Price MR, Sheehan JK. Respiratory mucins: identification of core proteins and glycoforms. Biochem J. 1996;316(Pt 3):967-75.

121. Das B, Cash MN, Hand AR, et al. Tissue distribution of Murine Muc19/Smgc gene products. J Histochem Cytochem. 2009.

122. Young HW, Williams OW, Chandra D, et al. Central role of Muc5ac expression in mucous metaplasia and its regulation by conserved $5^{\prime}$ elements. Am J Respir Cell Mol Biol. 2007;37(3):273-90.

123. Thornton DJ, Rousseau K, McGuckin MA. Structure and function of the polymeric mucins in airways mucus. Annu Rev Physiol. 2008;70:459-86.

124. Hovenberg HW, Davies JR, Carlstedt I. Different mucins are produced by the surface epithelium and the submucosa in human trachea: identification of MUC5AC as a major mucin from the goblet cells. Biochem J. 1996;318(Pt 1):319-24.

125. Wickstrom C, Davies JR, Eriksen GV, Veerman EC, Carlstedt I. MUC5B is a major gel-forming, oligomeric mucin from human salivary gland, respiratory tract and endocervix: identification of glycoforms and C-terminal cleavage. Biochem J. 1998;334(Pt 3):685-93.

126. Zuhdi Alimam M, Piazza FM, Selby DM, Letwin N, Huang L, Rose MC. Muc-5/5ac mucin messenger RNA and protein expression is a marker of goblet cell metaplasia in murine airways. Am J Respir Cell Mol Biol. 2000;22(3):253-60.

127. Guo X, Pace RG, Stonebraker JR, et al. Mucin variable number tandem repeat polymorphisms and severity of cystic fibrosis lung disease: significant association with MUC5AC. PLoS One. 2011;6(10):e25452.

128. Evans CM, Kim K, Tuvim MJ, Dickey BF. Mucus hypersecretion in asthma: causes and effects. Curr Opin Pulm Med. 2009;15(1):4-11.

129. Roy MG, Rahmani M, Hernandez JR, et al. Mucin production during pre- and post-natal mouse lung development. Am J Respir Cell Mol Biol. 2011.

130. Ordonez CL, Khashayar R, Wong HH, et al. Mild and moderate asthma is associated with airway goblet cell hyperplasia and abnormalities in mucin gene expression. Am J Respir Crit Care Med. 2001;163(2):517-23.

131. Hallstrand TS, Debley JS, Farin FM, Henderson Jr WR. Role of MUC5AC in the pathogenesis of exercise-induced bronchoconstriction. J Allergy Clin Immunol. 2007;119(5): 1092-8.

132. Seibold MA, Wise AL, Speer MC, et al. A common MUC5B promoter polymorphism and pulmonary fibrosis. N Engl J Med. 2011;364(16):1503-12.

133. Mata M, Morcillo E, Gimeno C, Cortijo J. N-acetyl-L-cysteine (NAC) inhibit mucin synthesis and pro-inflammatory mediators in alveolar type II epithelial cells infected with influenza virus A and B and with respiratory syncytial virus (RSV). Biochem Pharmacol. 2011;82(5):548-55.

134. Shimizu T, Takahashi Y, Kawaguchi S, Sakakura Y. Hypertrophic and metaplastic changes of goblet cells in rat nasal epithelium induced by endotoxin. Am J Respir Crit Care Med. 1996;153(4 Pt 1):1412-8. 
135. Nie YC, Wu H, Li PB, et al. Characteristic comparison of three rat models induced by cigarette smoke or combined with LPS: to establish a suitable model for study of airway mucus hypersecretion in chronic obstructive pulmonary disease. Pulm Pharmacol Ther. 2012.

136. Sueyoshi S, Miyata Y, Masumoto Y, et al. Reduced airway inflammation and remodeling in parallel with mucin $5 \mathrm{AC}$ protein expression decreased by s-carboxymethylcysteine, a mucoregulant, in the airways of rats exposed to sulfur dioxide. Int Arch Allergy Immunol. 2004;134(4):273-80.

137. Wagner JG, Van Dyken SJ, Wierenga JR, Hotchkiss JA, Harkema JR. Ozone exposure enhances endotoxin-induced mucous cell metaplasia in rat pulmonary airways. Toxicol Sci. 2003;74(2):437-46.

138. Bein K, Leikauf GD. Acrolein - a pulmonary hazard. Mol Nutr Food Res. 2011;55(9):1342-60.

139. Breuer R, Christensen TG, Lucey EC, Bolbochan G, Stone PJ, Snider GL. Elastase causes secretory discharge in bronchi of hamsters with elastase-induced secretory cell metaplasia. Exp Lung Res. 1993;19(2):273-82.

140. Voynow JA, Fischer BM, Malarkey DE, et al. Neutrophil elastase induces mucus cell metaplasia in mouse lung. Am J Physiol Lung Cell Mol Physiol. 2004;287(6):L1293-1302.

141. Turner J, Jones CE. Regulation of mucin expression in respiratory diseases. Biochem Soc Trans. 2009;37(Pt 4):877-81.

142. Polosukhin VV, Cates JM, Lawson WE, et al. Hypoxia-inducible factor-1 signalling promotes goblet cell hyperplasia in airway epithelium. J Pathol. 2011;224(2):203-11.

143. Tsao PN, Wei SC, Wu MF, et al. Notch signaling prevents mucous metaplasia in mouse conducting airways during postnatal development. Development. 2011;138(16):3533-43.

144. Lai H, Rogers DF. New pharmacotherapy for airway mucus hypersecretion in asthma and COPD: targeting intracellular signaling pathways. J Aerosol Med Pulm Drug Deliv. 2010;23(4): 219-31.

145. Poole PJ, Black PN. Preventing exacerbations of chronic bronchitis and COPD: therapeutic potential of mucolytic agents. Am J Respir Med. 2003;2(5):367-70.

146. Vestbo J, Prescott E, Lange P. Association of chronic mucus hypersecretion with FEV1 decline and chronic obstructive pulmonary disease morbidity. Copenhagen City Heart Study Group. Am J Respir Crit Care Med. 1996;153(5):1530-5.

147. Poole PJ, Black PN. Mucolytic agents for chronic bronchitis or chronic obstructive pulmonary disease. Cochrane Database Syst Rev. 2006;3, CD001287.

148. Decramer M, Rutten-van Molken M, Dekhuijzen PN, et al. Effects of $\mathrm{N}$-acetylcysteine on outcomes in chronic obstructive pulmonary disease (Bronchitis Randomized on NAC CostUtility Study, BRONCUS): a randomised placebo-controlled trial. Lancet. 2005;365(9470):1552-60.

149. Gerrits CM, Herings RM, Leufkens HG, Lammers JW. Nacetylcysteine reduces the risk of re-hospitalisation among patients with chronic obstructive pulmonary disease. Eur Respir J. 2003;21(5):795-8.

150. Zuin R, Palamidese A, Negrin R, Catozzo L, Scarda A, Balbinot M. High-dose $\mathrm{N}$-acetylcysteine in patients with exacerbations of chronic obstructive pulmonary disease. Clin Drug Investig. 2005;25(6): 401-8.

151. Zheng JP, Wen FQ, Bai CX, et al. High-dose N-acetylcysteine in the prevention of COPD exacerbations: rationale and design of the PANTHEON Study. COPD. 2012;9:1-8.

152. Guizzardi F, Rodighiero S, Binelli A, et al. S-CMC-Lys-dependent stimulation of electrogenic glutathione secretion by human respiratory epithelium. J Mol Med (Berl). 2006;84(1):97-107. 